\title{
Forests and their genetics
}

Tropical Rain Forests of the Far East. By T. C. Whitmore. With a chapter on soils by C. P. Burnham. Pp. xiii +282 . (Clarendon: Oxford; Oxford University: London, December 1975.) £12.50.

THIS is a superb book. I dearly wish that it had been available before I made my first visit to a tropical rain forest. The title is accurate but unduly modest. The book indeed treats tropical rain forests of the Far East exhaustively, but in a surprisingly compact and literate form. The author's approach, however, is so broadly interpretive that much of what he says gives equal insight into other tropical forests.

In addition to chapters on geography, climate, and forest structure, there are excellent separate chapters and dispersed notes on silviculture, animals, and the interactions between plants and animals.

Much of the interpretive study of tropical forests has suffered from overgeneralisation followed by nihilistic reaction. Whitmore gives refreshingly balanced discussions of topics such as storied vegetation, lateritic soils, buttressed roots, and compound leaves. He reviews recent theories of the structure and economy of tropical forests with a healthy mixture of enthusiasm and agnosticism. His extensive field experience is apparent in many practical hints about what one should look for when identifying trees or reading a landscape.

The book is abundantly illustrated with elegant photographs, each taken under technically taxing conditions and each showing its ecological point remarkably well. Cross-references among chapters are unusually apt and easy to follow. The bibliography is copious, selected with acute judgement, and up to date within a year of its publication. The free use of botanical cryptology is a deterrent to the wide 'browsership' that the book deserves; but it is not an insurmountable difficulty, since arcane terms are defined where they first occur. A glossary would have helped.

Whitmore ends most of his critical discussions with an explicit list of data that are needed to evaluate interpreta tions of previous observations. His book should therefore be especially valuable to graduate students and ad- vanced undergraduates. It is both successor and complement to P. W. Richard's classic The Tropical Rain Forest (1952, Cambridge University Press).

A final section on human use is a succinct, rational, and eloquent plea for conservation of some remaining unexploited forests, and for applying natural history and common sense to the management of exploited areas.

Henry S. Horn

Introduction to Forest Genetics. By Jonathan W. Wright. Pp. xvi +463. (Academic: New York and London, February 1976.) $\$ 19.50$; $£ 10.15$.

Srudy or use of genetic variation in forest trees began early in the last century but systematic application of genetic principles to the domestication of trees began only 50 years ago. Through the last 30 years there has been a dramatic increase in activity with programmes for population testing and selective breeding being initiated in many countries, with many species, and for many different types of forest products.

Professor Wright has long been one of the leading practitioners and teachers of forest genetics and tree improvement in North America where, together with northern Europe, most of the early work was done and where the larger and most advanced programmes are located. One of the few criticisms of this book arises from that; the bulk of the examples and the references quoted are from the temperate regions of North America and Europe with some from Japan, New Zealand and South America; tropical species and areas in which there is now much activity and rapid progress, receive scant attention. Although this may detract from the value of the book as a worldwide review it does not affect the principle aim, which is to provide an introductory text for future professional tree breeders.

In 1962, at the request of the United Nations Food and Agriculture Organisation Professor Wright prepared Genetics of Forest Tree Improvement (FAO Forestry and Forest Product Studies No. 16, Rome). Until now this has remained the only textbook in English on the subject and for several years it has been unobtainable.
The present book is a revision of the 1962 study with updated examples and illustrations and none of the errors that marred the first book. It does not assume great previous knowledge of genetics or statistics; throughout, the book has a pleasing balance between theory and practice. Less pleasing is the imbalance in the bibliographic citations in the various chapters; some controversial statements are made dogmatically and unsupported by literature citations, whereas others are supported unnecessarily by large numbers of references.

The subject matter covers basic concepts of Mendelian and quantitative genetics in the first five chapters, although a consideration of chromosomes themselves (polyploidy, aneuploidy and haploidy) is deferred until the last (nineteenth) chapter. The remaining chapters are the core of practical tree improvement covering the four most common approaches to tree improvement: individual tree selection and breeding; provenance testing; species and racial hybridisation; introduction of exotics. A useful glossary and adequate index are provided.

This book holds something of value to all foresters and crop breeders. It is a basic reference for tree breeders and essential for all courses in forest genetics and tree improvement.

J. Burley

\section{Nuclear magnetic resonance}

NMR in Biological Research: Peptides and Proteins. By Kurt Wüthrich. Pp. $x i i+379$. (North-Holland: Amsterdam and Oxford; American Elsevier: New York, 1976.) \$45.95; Dfl.115.

THE increasing interest in the application of nuclear magnetic resonance (NMR) techniques to biological problems is reflected in the spate of books and review articles which have recently appeared on the subject. Professor Wüthrich's book is a valuable addition to this collection in that he has produced an ideal text for introducing the chemist or biochemist into this area of research. The main emphasis of the book is on illustrating the different kinds of biologically relevant information which can be 